\title{
Reconstrucción mandibular con implante hecho a medida de polieteretercetona
}

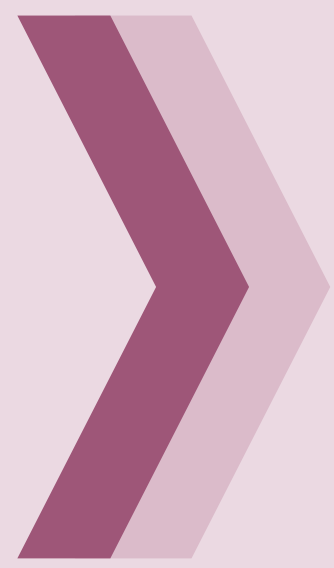

\author{
Mandibular reconstruction \\ with polyetheretherketone \\ computer designed implant
}

Juan Francisco Oré-Acevedo,' Katerin Castillo-Chávez, ${ }^{2}$ Walter Huaranga-Bustamante ${ }^{3}$

I. Médico asistente de Cirugía de Cabeza, Cuello y Maxilofacial Hospital Militar Central (HMC). Lima, Perú.

2. Cirujano dentista asistente de Cirugía Bucal y Maxilofacial Instituto Nacional de Salud del Niño Lima, Perú.

3. Cirujano Dentista Asistente de Cirugía Bucal y Maxilofacial HMC

\section{RESUMEN}

Se describe el caso de un varón de 21 años, que ingresa a emergencia por sufrir un traumatismo, por arma de fuego de alta velocidad. El área comprometida es el tercio inferior facial, con extensión a las regiones submentoniana y submandibulares. El paciente presentó una fractura conminuta en la mitad inferior mandibular y dos fracturas con desplazamiento en la mitad superior mandibular, sin pérdida ni compromiso de piezas dentarias. Posterior a la reducción cruenta y osteosíntesis con alambre quirúrgico realizada en emergencia, en la reconstrucción se utilizó un implante hecho a medida basado en imágenes tomográficas. El implante de polieteretercetona (PEEK) fue seleccionado para reemplazar la pérdida ósea y para restaurar la anatomía facial. Los implantes de PEEK son actualmente una nueva opción biocompatible, simple y versátil para reconstrucciones mandibulares complejas Se presentan las imágenes tomográficas antes y después del implante, imágenes del paciente antes y después del implante y el proceso quirúrgico de implante.

Palabras clave. Mandíbula, reconstrucción, implante, prótesis, polietetercetona.

\begin{abstract}
A 22 years old male was referred to emergency for a gunshot trauma that involves the inferior third of the face with extension to the both submandibular and submental regions. The patient presented at the inferior half of the mandible, bodies and symphysis, a comminuted mandible fracture and two displaced fractures at the upper half of the mandible; though no teeth were missing. He underwent at emergency an open reduction and osteosynthesis with wires. A polyetheretherketone (PEEK) computer designed implant was placed to replace the lost bone tissue and restore the facial aesthetics. The PEEK implant is actually a new, simple and versatile method for complex mandibular reconstructions.
\end{abstract}

KEY WORDS. Mandible, reconstruction, implant, prosthesis, polyetheretherketone. 


\section{Anta Méaica Pernana}

\section{INTRODUCCIÓN}

Los traumatismos de cabeza y cuello producidos por arma de fuego de alta velocidad tienen como consecuencia defectos irregulares y de gran tamaño, incluso mayores que las resecciones oncológicas, y que involucran diferentes regiones. El alto grado de destrucción puede involucrar las partes blandas, estructurasóseas, vasos sanguíneos, nervios y órganos, y crear comunicaciones con la cavidad oral, nasal o los senos paranasales. Por lo tanto, estos traumatismos requieren de reconstrucciones de alta complejidad y, la mayoría de casos, en intervenciones separadas. Además de la emergencia, por el sangrado masivo que puede comprometer la vía aérea o digestiva.
El objetivo de este artículo es mostrar un método de reconstrucción mandibular con un material relativamente nuevo, con uso de la tecnología actual, para producir implantes personalizados con base en datos tomográficos. Se reporta un caso de implante mandibular de polieteretercetona (PEEK).

\section{REPORTE DE CASO}

Un paciente varón de 21 años de edad ingresa a emergencia por sufrir un traumatismo causado por arma de fuego de alta velocidad. El traumatismo compromete partes blandas y estructuras óseas del tercio inferior facial, la región submentoniana y ambas espacios submandibulares. El paciente
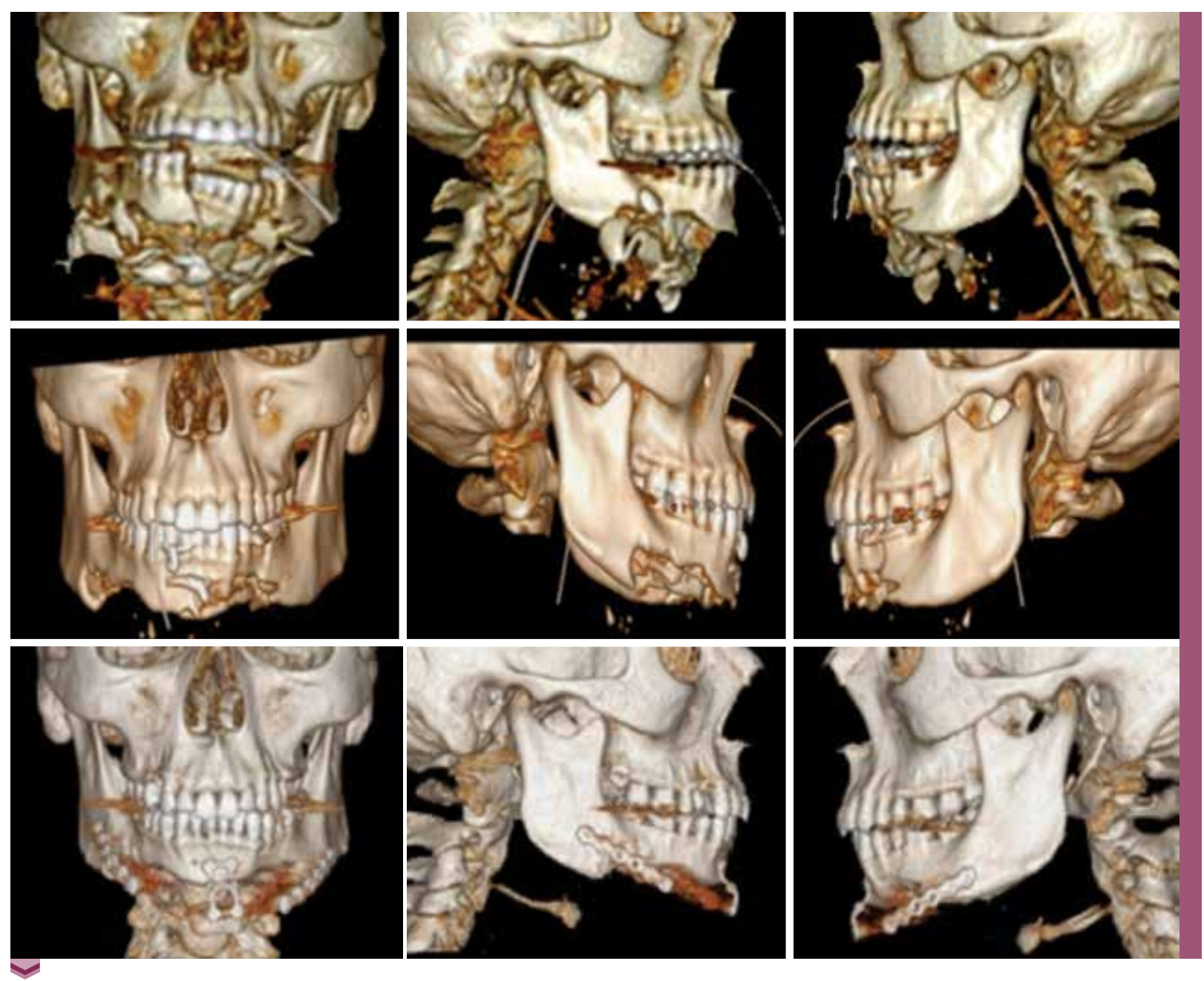

Figura 1. Arriba: tomografía del macizo facial al ingreso del paciente por emergencia. Al medio: tomografía después de la limpieza quirúrgica, reducción cruenta y osteosíntesis con alambre quirúrgico. Abajo: tomografía después de la colocación del implante y osteosíntesis respectiva. 
presenta una herida contaminada y con sangrado activo. A pesar del alto grado de destrucción, no existe ninguna pérdida de piezas dentarias.

Las imágenes de tomografía muestran dos fracturas desplazadas en la mitad superior de la mandíbula, una parasinfisiaria derecha y otra en el cuerpo mandibular izquierdo. Asimismo, una fractura conminuta en la mitad inferior de ambos cuerpos mandibulares y de todo el mentón, pero sin comprometer ambos ángulos de la mandíbula. Figura 1.

Se procedió en la cirugía de emergencia a un control del sangrado y limpieza quirúrgica con desbridamiento de tejido desvitalizado y al retiro de cuerpos extraños y de los segmentos óseos conminutados. También se realizó una reducción cruenta y fijación con alambre quirúrgico, a nivel del segmento dentoalveolar y subapical, con alambrado bicortical. El paciente quedó sin fijación intermaxilar, debido al restablecimiento anatómico de la arcada dentaria inferior, para restaurar la oclusión. Durante las dos primeras semanas del postoperatorio, se le administró dieta blanda, cobertura antibiótica amplia y analgésicos respectivos. Figura 2.

En el postoperatorio, el paciente presenta la oclusión restaurada, pero se evidencia el defecto mandibular a nivel de ambos cuerpos y del mentón, así como anestesia en el territorio de ambos nervios mentonianos. En ningún momento fue necesaria la realización de una traqueostomía. Los estudios de imágenes como la radiografía panorámica y la tomografía computarizada corroboran la reducción de los segmentos dentoalveolares y la evidencia de la zona del defecto óseo mandibular.
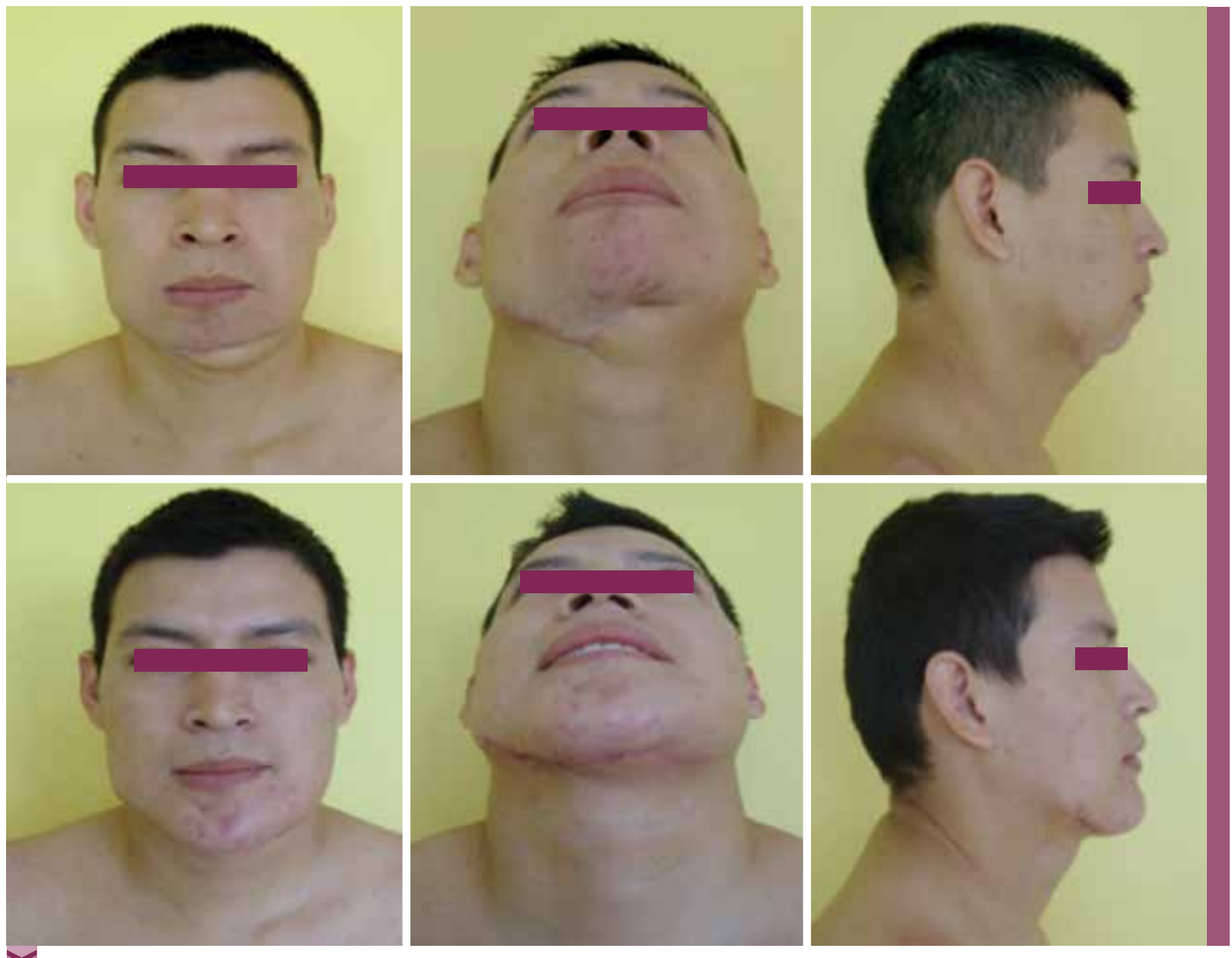

Figura 2. Arriba: paciente antes de la colocación del implante. Abajo: paciente después de la colocación del implante de polieteretercetona. 


\section{Anta Méaica Pernana}

Con los datos de la tomografía, se solicitó la confección de un implante confeccionado de PEEK.

En la cirugía reconstructiva, se realizó una incisión cervical, a través de la cicatriz, previa profilaxis, con $1 \mathrm{~g}$ de cefazolina. Después del levantamiento de los colgajos superior e inferior, se realizó el retiro del alambrado bicortical previo y el fresado y la remoción del callo óseo a nivel de los bordes mandibulares, para el colocado del implante (Figura 3).

Para la osteosíntesis a nivel de ambos cuerpos mandibulares, se utilizó una placa con sistema de bloqueo 2.0. La fijación fue realizada con un tornillo de bloqueo y uno sin sistema de bloqueo en posiciones distal y proximal, respectivamente, al borde de unión de la mandíbula con el implante. Además, se colocó una placa subapical, de bajo perfil, a nivel de los incisivos centrales, para evitar la rotación horaria del implante. No se utilizaron sistemas de drenaje para evitar la contaminación, se aplicó un apósito compresivo con vendaje a nivel submentoniano.
Fue dado de alta tres semanas posterior a la cirugía, con restauración de la anatomía mandibular. Durante el año posterior a la cirugía, no se presentaron complicaciones, el paciente presentó una apertura bucal sin alteraciones y con capacidad de comer una dieta completa.

\section{DISCUSIÓN}

Los huesos del macizo facial poseen una anatomía tridimensional compleja, motivo por el que en su reconstrucción se necesita restablecer no solo la función, sino también la estética facial.

Los traumatismos por armas de fuego de alta velocidad no solo dejan tejido fibroso, sino que también destruyen los vasos sanguíneos necesarios para una microcirugía; lo que compromete la vascularidad del área quirúrgica y la hace poco viable para injertos óseos libres, con lo que se eleva la tasa de reabsorción del injerto.

Diversos materiales aloplásticos han sido usados en la fabricación de implantes diseñados con base
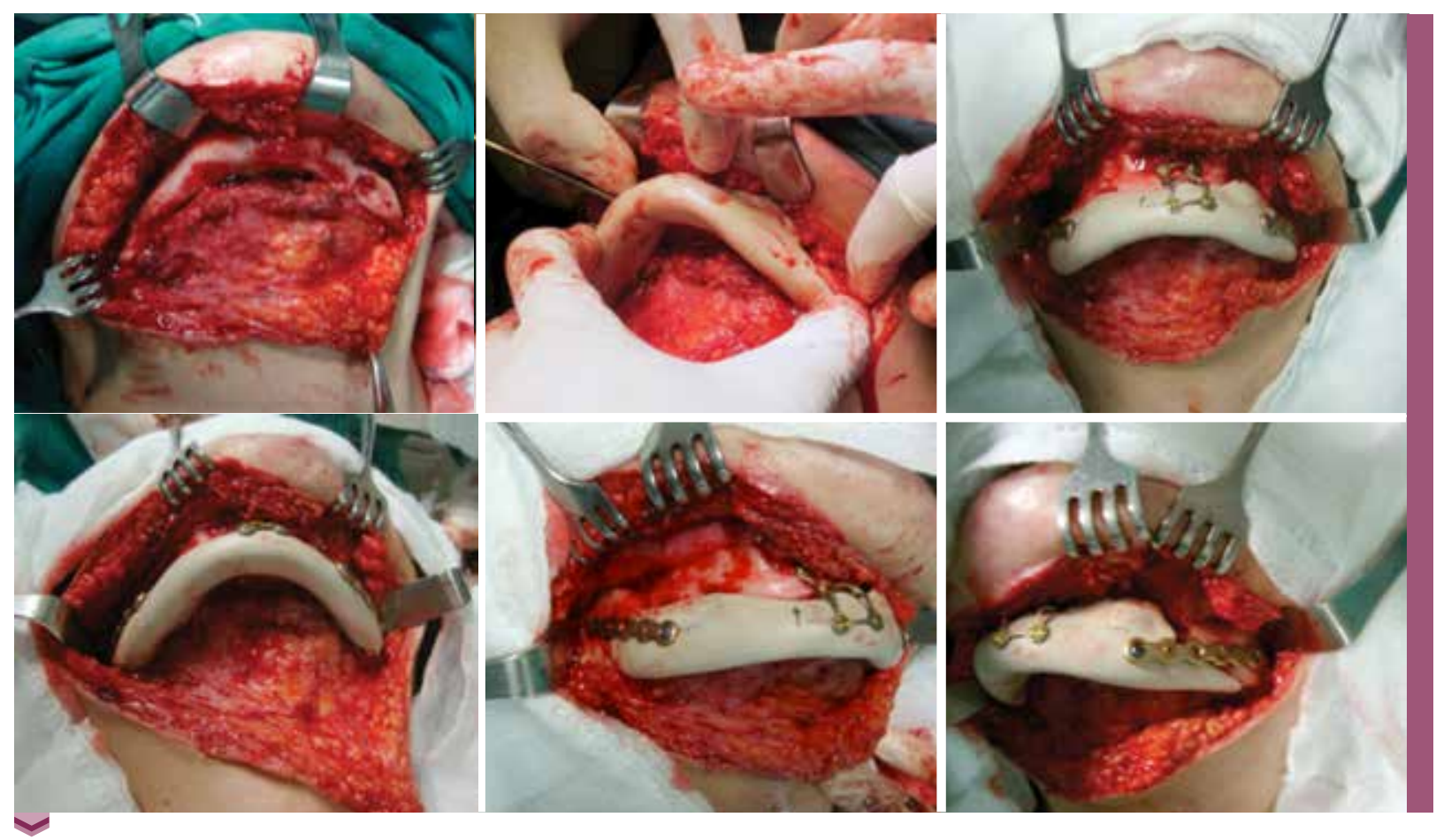

Figura 3. Arriba: exposición del defecto mandibular, previo fresado del callo óseo a nivel del borde inferior mandibular y prueba in vivo del encaje del implante al defecto mandibular. Al medio: vista frontal e inferior de la anatomía mandibular con el implante. Abajo: vistas laterales; se observa placa unilock para osteosíntesis, con respeto de la línea basal mandibular. 
en datos de tomografía, como titanio, polietileno de alta densidad y PEEK. Los dos últimos son radiolúcidos, no son visibles en las radiografías o las tomografías y generan mínima formación de artefactos en la resonancia magnética.

El uso de implantes diseñados a medida elude la morbilidad de un área donante y disminuye el tiempo quirúrgico, debido a que se evita la toma del modelo y el moldeado del injerto óseo a colocar. ${ }^{1-9}$ Si hay que realizar algún pequeño ajuste a la zona de unión, se recomienda la corrección en el borde óseo, mas no en el implante; se acopla el paciente al implante y no viceversa. . $^{1-4,10-14}$

\section{REFERENCIAS BIBLIOGRÁFICAS}

I. Casallo C, Tantas G, Pineda R. Craneoplastía con implante de polieteretercetona diseñado por computadora. Acta Med Peruana. 2010; 27(3):193-195.

2. Goodson ML, Farr D, Keith D, Banks RJ. Use of two-piece polyetheretherketone (PEEK) implants in orbitozygomatic reconstruction. Br J Oral Maxillofac Surg. 2012; 50(3):268-269.

3. Bin Lai J, Sittitavornwong S,Waite P. Computer-assisted designed and computer-assisted manufactured polyetheretherketone prosthesis for complex fronto-orbito-temporal defect. J Oral Maxillofac Surg. 201 I;69(4): I I75- I 180.

4. Abdullakutty A, Madhavarajan S, Collyer J, Sneddon K. Uses of PEEK in maxillofacial reconstruction: a 6 year review of cases. $\mathrm{Br}$ J Oral Maxillofac Surg. 2012; 50(I):S39-S40.

5. Scolozzi P, Martinez A, Jaques B. Complex orbito-frontotemporal reconstruction using computer-designed PEEK implant. J Craniofac Surg. 2007; I8(I):224-228.

6. Frodel JL Jr. Computer-designed implants for fronto-orbital defect reconstruction. Facial Plast Surg. 2008;24(I):22-34.

7. Hanasono MM, Goel N, DeMonte F. Calvarial reconstruction with polyetheretherketone implants. Ann Plast Surg. 2009;62(6): 653-655.

\section{CONCLUSIÓN}

Los implantes hechos a medida de polieteretercetona (PEEK) son una muy buena opción para la reconstrucción de los defectos complejos en el ángulo, cuerpo o sínfisis mandibular, de mediano o gran tamaño, pero que no involucran el reborde dentoalveolar. Los implantes diseñados son confeccionados para recrear la anatomía mandibular con gran precisión en tamaño y forma. La técnica quirúrgica es simple y requiere un tiempo mucho menor que otras procedimientos de reconstrucción, sin el uso de un área de tejido donante.

8. Sobieraj MC, Kurtz SM, Rimnac CM. Notch sensitivity of PEEK in monotonic tension. Biomaterials. 2009;30(33):6485-6494.

9. Kurtz SM, Devine J.PEEK biomaterials in trauma, orthopedic, and spinal implants. Biomaterials. 2007;28(32):4845-4869.

10. Foletti JM, Lari N, Dumas P, Compes P, Guyot L. Reconstruction esthétique de la voûte crânienne par implant sur mesure en PEEK. Rev Stomatol Chir Maxillofac. 20 I 2; I 3(6):468-47। .

II. Frederic L, Jalbert F, Bessard J, Boutault F, Roux E, Schmidt E, Boetto S. PEEK implants for cranioplasty of complex cranial defects.J Cranio Maxill Surg. 2008;36(I):S204-S205.

12. Racine C, Raffoul W, Martinez A, Broome M. Reconstruction fronto-orbitaire complexe avec prothèse en PEEK et expansion cutanée: à propos d'un cas. Rev Stomatol Chir Maxillofac. 2012; I I3(6):46I-464.

13. Pace C, Holt D. The use of polyetheretherketone (PEEK) in zygomatico-orbital reconstruction. $\mathrm{Br} \mathrm{J}$ Oral Maxillofac Surg. 20I0;48(I):36.

14. Lethaus B, Poort ter Laak M, Laeven P, Beerens M, Koper D, Poukens J, Kessler P. A treatment algorithm for patients with large skull bone defects and first results. J Cranio Maxill Surg. 20II;39(6):435-440.

\section{Correspondencia \\ Dr. Juan F. Oré-Acevedo \\ juanfcoore@yahoo.com}

\section{Conflictos de interés}

Los autores declaran no tener conflictos de interés durante el planteamiento, ejecución de la investigación y la elaboración del artículo para su publicación.

Fecha de recepción: 14 de febrero de 2014.

Fecha de aceptación: 24 de marzo de 2014. 